\title{
Anticoagulant Activity of Crude and Phenolic Extracts of Dalbergia ecastaphyllum (L.) Taub. Dried Leaves
}

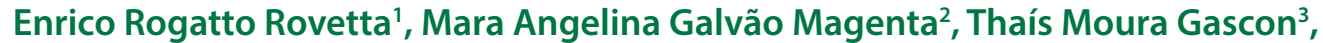 \\ Fernando Luiz Affonso Fonseca ${ }^{3}$, Robson Miranda da Gama ${ }^{1}$, José Armando Jr ${ }^{1}$, Horácio Dorigan Moya ${ }^{1, *}$
}

\section{Enrico Rogatto Rovetta', Mara Angelina Galvão Magentaㄹ ${ }^{2}$ Thaís Moura Gascon ${ }^{3}$, Fernando Luiz Affonso Fonseca ${ }^{3}$, Robson Miranda da Gama ${ }^{1}$, José Armando $\mathrm{Jr}^{1}$, Horácio Dorigan Moya ${ }^{1, *}$}

${ }^{1}$ Centro Universitário FMABC, Pharmacy Laboratory, Santo André, São Paulo, BRAZIL.

${ }^{2}$ Universidade Santa Cecília, Santos, São Paulo, BRAZIL.

${ }^{3}$ Centro Universitário FMABC, Clinical Analysis Laboratory, Santo André, São Paulo, BRAZIL. ${ }^{4}$ Centro Universitário FMABC, Analytical Chemistry Laboratory, Santo André, São Paulo, BRAZIL.

Correspondence

Dr. Horácio Dorigan Moya

Faculdade de Medicina da Fundação do ABC - Av. Príncipe de Gales, 821 - CEP 09060 - 650 Santo André, BRAZIL.

Phone no: +55 11 4993-7292

Email id: horacio.moya@fmabc.br

History

- Submission Date: 03-01-2021;

- Review completed: 23-02-2021;

- Accepted Date: 15-05-2021

DOI : 10.5530/pres.13.3.3

Article Available online

http://www.phcogres.com

\section{Copyright}

(c) 2021 Phcog.Net. This is an openaccess article distributed under the terms of the Creative Commons Attribution 4.0 International license.

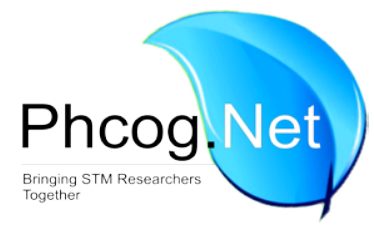

\begin{abstract}
Background: Ischemic diseases are one of the leading causes of death worldwide; therefore, the search for new compounds with safer and more effective anticoagulant and antiplatelet action becomes relevant. Objectives: To evaluate the impact of Dalbergia ecastaphyllum (L.) Taub. dry leaf extract, a species of the Fabaceae family that is commonly found in Brazil, on blood coagulation. Materials and Methods: A statistical design of experiments was carried out with selection of five factors and two levels, resulting in 32 different ethanolic raw extracts. The extracts were resuspended in saline and tested in a pool of human blood. The activated partially thromboplastin time (APTT) and the prothrombin time (PT) were analysed in a Thrombolyzer ${ }^{\circledR}$. Results: Treatment using ethanol 70\%, a drug/solvent ratio of $5 \%$, pH 9 and dynamic maceration for 6 hrs resulted in the best combination for the extraction of total phenols, while ethanol $70 \%$, a drug/solvent ratio of $5 \%$ and dynamic maceration for $24 \mathrm{hrs}$ showed the best flavonoid extraction, with the $\mathrm{pH}$ being inconclusive. On average, all extracts were capable of increasing both APTT and PT, especially those in lower dilutions (1:5); however, the overall efficacy of the extracts is inconclusive. Conclusion: The species under study showed important results in the blood clotting process in vitro, increasing the mean time of APTT and PT, which suggests that Dalbergia ecastaphyllum (L.) Taub. has some potential as a possible drug in the anticoagulant class.
\end{abstract}

Key words: Anticoagulant activity, Dalbergia ecastaphyllum (L.) Taub., Flavonoids, Phenolic compounds, Plant extracts.

\section{INTRODUCTION}

The blood tissue works in a perfect balance to control its own haemostasis by a complex coagulation process that prevents leakage by blocking the passage through the vessels. The defence mechanism for blood loss through vascular injury is controlled by the haemostatic system through vasoconstriction at the injury site, platelet aggregation and blood coagulation, which stabilizes and sustains the thrombus. ${ }^{[1]}$

When the haemostatic system works properly, the blood is kept inside the vessels by thrombus formation in the case of an endothelium injury and, after the tissue is repaired, the thrombus is fragmented and the blood circulates normally. ${ }^{[2]}$ However, when this process is unregulated, there may be complications in the vascular system, such as ischemic diseases, thrombosis or haemorrhage through intrinsic platelet dysfunction, von Willebrand disease or by antiplatelet agent actions, for example. ${ }^{[3]}$ Thus, it is of great interest to discover new antiplatelet and anticoagulant drugs, which could be more efficient in comparison to those currently used, providing a prolonged effect and showing less harmful effects on the patients, than drugs such as aspirin and clopidogrel, among others. ${ }^{[4]}$
At least a quarter of current pharmaceutical products were originally obtained from medical plants and most of these plants are responsible for the origination of analgesic, anti-inflammatory and antipyretic drugs. ${ }^{[5]}$

There are several mechanisms of action that are still unknown, therapeutic targets to be explored and effects that can be of great use; the possibilities for the use of medical plants are therefore diverse. ${ }^{[6]}$ In Brazil, the flora biodiversity is abundant and consists of several bioactive substances that can show important benefits in numerous pathologies, coagulation disorders among them. ${ }^{[7]}$

Dalbergia is a large genus of the Fabaceae family; it consists of more than 200 species, which are widespread in tropical and subtropical regions. The parts most commonly used in the majority of research to understand its pharmacological effect on traditional medicine are the leaves, bark and root. ${ }^{[8]}$ In Brazil, a coastal species is typical, occurring from the northeast to the southern region. Traditionally, it has been used for uterine inflammation and 
anaemia. ${ }^{[9]}$ In this paper, the optimization of plant material extraction and its impact on human blood coagulation by different fractions of total phenols and flavonoids is presented.

\section{MATERIALS AND METHODS}

\section{Plant material}

The plant material consisted of Dalbergia ecastaphyllum (L.) Taub. leaves were collected at the Iporanga Allotment, which belongs to the Environmental Protection Area (APA) of Serra do Guararú, Guarujá-SP, Brazil in July 2016 (Sisgen code: AE5F32C). After collection, leaves were dried to a constant weight at $50^{\circ} \mathrm{C}$ (in a dry air chamber). Dry material was obtained by grinding the leaves to a powder using a knife mill (Marconi $^{\text {Tix }}$ MA 048).

\section{Phytochemical screening}

Analytical tests were performed using dried leaf powder of Dalbergia ecastaphyllum (L.) Taub. to detect the presence of secondary metabolites (total phenols, alkaloids, tannins, flavonoids, saponins, anthraquinone and cardiotonic glycosides) using qualitative experimental methods. ${ }^{[10,11]}$

\section{Quantitative analysis}

An experimental statistical design was performed (DoE, Minitab ${ }^{\circledR}$, selecting 5 factors by 2 levels (absolute ethanol or ethanol 70\%; drug/ solvent ratio at $5 \%$ or $10 \%$; $\mathrm{pH} 3$ or $\mathrm{pH}$ 9; static or dynamic maceration for $24 \mathrm{hrs}$ or $6 \mathrm{hrs}$ ), resulting in 32 different ethanolic raw extracts (ERE) (Table 1 and 2). The ERE were stored in a freezer at $-20^{\circ} \mathrm{C}$ for quantitative analysis and were evaporated to dryness in a rotary evaporator (Fisatom ${ }^{\text {rox }}$ 802) to obtain the aqueous raw fraction (ARF) for the complete blood count $(\mathrm{CBC})$. Non-purified extracts were resuspended in saline water to obtain a saline aqueous extract (SAE).

\section{Total phenol quantification}

The quantification of total phenol content of the dried leaf extract was obtained by spectrophotometry analysis. ${ }^{[12,13]}$ In order to better assess which combination of factors had the greatest influence on the extraction process of total phenols, the spectrophotometer was used to perform the standard curve in triplicate with a GEHAKA UV ${ }^{\circledR}$ device, model 330G, at a wavelength of $510 \mathrm{~nm} \cdot{ }^{[12,13]}$

\section{Flavonoids quantification}

The quantification of flavonoid content of the dried leaf extract was obtained by spectrophotometry analysis. ${ }^{[14]}$ The standard curve for flavonoids was obtained by quercetin and aluminium chloride solutions. The absorbance was read in triplicate using a spectrophotometer GEHAKA UV ${ }^{\circledR}$ device, model 330G, at a wavelength of $415 \mathrm{~nm} .^{[14]}$

Table 1: Levels and factors of the statistical design of experiments for 32 trials (DoE, Minitab).

\begin{tabular}{ccc}
\hline Factors & Level $(-1)$ & Level $(+1)$ \\
\hline Solvent & $70 \%$ ethanol & $100 \%$ ethanol \\
Drug/solvent ratio & $5: 100$ & $10: 100$ \\
Time & $6 \mathrm{hrs}$ & $24 \mathrm{hrs}$ \\
$\mathrm{pH}$ & Acid $(\mathrm{pH}=3)$ & Alkali $(\mathrm{pH}=9)$ \\
Maceration & Static & Dynamic \\
\hline
\end{tabular}

\section{Purified total phenol fraction}

The ARF originating from the best extraction condition (ethanol 70\%; a drug/solvent ratio of 5\%; $\mathrm{pH} 9$ and dynamic maceration for $6 \mathrm{hrs}$ ) was adjusted to $\mathrm{pH} 11$ using $\mathrm{NH}_{4} \mathrm{OH} 50 \%$ solution and centrifuged at $4000 \mathrm{rpm}$ for $15 \mathrm{~min}$, followed by a liquid-liquid partition with 3 portions of chloroform. The purified fraction was corrected to $\mathrm{pH} 4$ using $\mathrm{HCl}$ $10 \%$ solution, followed by filtration through a funnel with glass wool and cotton. ${ }^{[15,16]}$ After purification, the extract was resuspended in saline water to obtain the purified total phenol SAE.

\section{Purified flavonoid fraction}

The ARF originating from the best extraction condition (ethanol 70\%; a drug/solvent ratio of 5\%; $\mathrm{pH} 9$ and dynamic maceration for $24 \mathrm{hrs}$ ) was submitted to consecutive extractions with different polarity solvents. The liquid-liquid partition was performed using 3 portions of petroleum ether, followed by 3 portions of chloroform and, finally, 3 portions of ethyl acetate. ${ }^{[17]}$ The purified fraction was corrected to $\mathrm{pH} 4$ using $\mathrm{HCl}$ solution $10 \%$, followed by filtration through a funnel with glass wool and cotton. After purification, the extract was resuspended in saline water to obtain the purified flavonoid SAE.

\section{Blood material}

Human blood was obtained from venous blood collected from 10 healthy patients (Brazilian Ethics Committee Approval: 08632919.9.0000.0082) from the Clinical Analysis Laboratory at Centro Universitário Saúde ABC and was kept in blood test tubes containing sodium citrate or ethylenediamine tetra-acetic acid (EDTA) as anticoagulants. ${ }^{[18]}$

The human blood samples were divided into two groups and both coagulation and haemogram were mixed and analysed on purified and non-purified SAE.

\section{Evaluation of coagulant activity}

The impact of purified and non-purified SAE plant extracts at four different dilutions $(1: 5,1: 10,1: 15$ and 1:20) on prothrombin time (PT) and activated partial thromboplastin time (APTT) was carried out using a haemostasis analyser (Start ${ }^{\text {tm }}$ - Diagnostica Stago), a commercial kit for PT (Thromboplastin Ds in lab haemostasis ${ }^{\mathrm{Tx}}$ ) and a BioTécnica ${ }^{\mathrm{Tx}}$ kit for APTT. The evaluation of PT and APTT parameters are relevant to understand the impact of the plant extracts on coagulation.

For PT analysis, $100 \mu \mathrm{L}$ of each of the four extract dilutions were added to test tubes containing $400 \mu \mathrm{L}$ of plasma. The samples were incubated at $37^{\circ} \mathrm{C}$ for $60 \mathrm{sec}$ in a Stago analyser ${ }^{\mathrm{rm}}$ to check the clot forming for coagulation assays.

For APTT analysis, $100 \mu \mathrm{L}$ of each of the four diluted extracts were added to test tubes containing $400 \mu \mathrm{L}$ of plasma. The samples were incubated for 180 seconds at $37^{\circ} \mathrm{C}$, in a Stago analyser ${ }^{\mathrm{rx}}$. All PT and APTT data using SAE were compared to blood and sodium citrate results and were conducted in triplicate.

\section{Blood count}

For the $\mathrm{CBC}, 100 \mu \mathrm{L}$ of each of the four diluted SAEs were added to test tubes containing $400 \mu \mathrm{L}$ of blood. The samples were analysed in a CBC analyser (Pentra $\left.{ }^{\text {Tx }} 120\right)$ to obtain the haemoglobin (HGB) and platelet (PLT) count; these results were compared to a blood control sample, which was prepared with $100 \mu \mathrm{L}$ of saline and $400 \mu \mathrm{L}$ of blood. 
Table 2: Factorial planning matrix for the $\mathbf{3 2}$ trials and the quantification of total phenols and flavonoids from different treatments.

\begin{tabular}{|c|c|c|c|c|c|c|c|}
\hline Extraction & Solvent & $\begin{array}{c}\text { Drug/ } \\
\text { solvent ratio }\end{array}$ & Time & $\mathrm{pH}$ & Maceration & $\begin{array}{c}\text { Total phenols average } \\
\pm \mathrm{SD}(\mathrm{mg} / \mathrm{g})\end{array}$ & $\begin{array}{c}\text { Flavonoids average } \pm \\
\text { SD }(\mu \mathrm{g} / \mathrm{g})\end{array}$ \\
\hline T1 & $70 \%$ ethanol & $5: 100$ & $6 \mathrm{hrs}$ & Acid $(\mathrm{pH}=3)$ & Static & $135.22 \pm 0.59$ & $58.07 \pm 0.17$ \\
\hline T2 & $70 \%$ ethanol & $5: 100$ & $6 \mathrm{hrs}$ & Acid (pH=3) & Dynamic & $159.38 \pm 0.47$ & $65.41 \pm 0.17$ \\
\hline T3 & $70 \%$ ethanol & $5: 100$ & $6 \mathrm{hrs}$ & Alkali $(\mathrm{pH}=9)$ & Static & $119.38 \pm 0.72$ & $99.83 \pm 0.17$ \\
\hline T4 & $70 \%$ ethanol & $5: 100$ & $6 \mathrm{hrs}$ & Alkali $(\mathrm{pH}=9)$ & Dynamic & $196.22 \pm 0.76$ & $155.24 \pm 0.45$ \\
\hline T5 & $70 \%$ ethanol & $5: 100$ & $24 \mathrm{hrs}$ & Acid (pH=3) & Static & $123.22 \pm 0.49$ & $93.33 \pm 0.17$ \\
\hline T6 & $70 \%$ ethanol & $5: 100$ & $24 \mathrm{hrs}$ & Acid (pH=3) & Dynamic & $107.88 \pm 0.54$ & $98.36 \pm 0$ \\
\hline T7 & $70 \%$ ethanol & $5: 100$ & $24 \mathrm{hrs}$ & Alkali $(\mathrm{pH}=9)$ & Static & $152.22 \pm 0.36$ & $97.1 \pm 0.17$ \\
\hline T8 & $70 \%$ ethanol & $5: 100$ & $24 \mathrm{hrs}$ & Alkali $(\mathrm{pH}=9)$ & Dynamic & $103.88 \pm 0.62$ & $117.25 \pm 0.3$ \\
\hline T9 & $70 \%$ ethanol & $10: 100$ & $6 \mathrm{hrs}$ & Acid (pH=3) & Static & $174.88 \pm 0.49$ & $62.72 \pm 0.15$ \\
\hline T10 & $70 \%$ ethanol & $10: 100$ & $6 \mathrm{hrs}$ & Acid $(\mathrm{pH}=3)$ & Dynamic & $135.28 \pm 0.61$ & $66.81 \pm 0.09$ \\
\hline T11 & $70 \%$ ethanol & $10: 100$ & $6 \mathrm{hrs}$ & Alkali $(\mathrm{pH}=9)$ & Static & $98.53 \pm 0.35$ & $65.66 \pm 0.15$ \\
\hline T12 & $70 \%$ ethanol & $10: 100$ & $6 \mathrm{hrs}$ & Alkali $(\mathrm{pH}=9)$ & Dynamic & $214.38 \pm 1.06$ & $134.7 \pm 0.34$ \\
\hline T13 & $70 \%$ ethanol & $10: 100$ & $24 \mathrm{hrs}$ & Acid (pH=3) & Static & $132.22 \pm 0.71$ & $64.92 \pm 0.15$ \\
\hline T14 & $70 \%$ ethanol & $10: 100$ & $24 \mathrm{hrs}$ & Acid (pH=3) & Dynamic & $172.55 \pm 0.49$ & $95.46 \pm 0.23$ \\
\hline T15 & $70 \%$ ethanol & $10: 100$ & $24 \mathrm{hrs}$ & Alkali $(\mathrm{pH}=9)$ & Static & $111.44 \pm 0.53$ & $75.41 \pm 0.09$ \\
\hline T16 & $70 \%$ ethanol & $10: 100$ & $24 \mathrm{hrs}$ & Alkali $(\mathrm{pH}=9)$ & Dynamic & $148.22 \pm 0.72$ & $118.96 \pm 0.31$ \\
\hline T17 & $100 \%$ ethanol & $5: 100$ & $6 \mathrm{hrs}$ & Acid (pH=3) & Static & $91.22 \pm 0.14$ & $42.75 \pm 0$ \\
\hline T18 & $100 \%$ ethanol & $5: 100$ & $6 \mathrm{hrs}$ & Acid (pH=3) & Dynamic & $85.55 \pm 0.36$ & $70.03 \pm 0.17$ \\
\hline T19 & $100 \%$ ethanol & $5: 100$ & $6 \mathrm{hrs}$ & Alkali $(\mathrm{pH}=9)$ & Static & $39.22 \pm 0.14$ & $43.38 \pm 0$ \\
\hline T20 & $100 \%$ ethanol & $5: 100$ & $6 \mathrm{hrs}$ & Alkali $(\mathrm{pH}=9)$ & Dynamic & $114.38 \pm 0.27$ & $80.94 \pm 0.17$ \\
\hline T21 & $100 \%$ ethanol & $5: 100$ & $24 \mathrm{hrs}$ & Acid (pH=3) & Static & $67.22 \pm 0.41$ & $63.32 \pm 0.17$ \\
\hline T22 & $100 \%$ ethanol & $5: 100$ & $24 \mathrm{hrs}$ & Acid $(\mathrm{pH}=3)$ & Dynamic & $139.05 \pm 0.54$ & $104.66 \pm 0.3$ \\
\hline T23 & $100 \%$ ethanol & $5: 100$ & $24 \mathrm{hrs}$ & Alkali $(\mathrm{pH}=9)$ & Static & $34.05 \pm 0.27$ & $44.43 \pm 0$ \\
\hline T24 & $100 \%$ ethanol & $5: 100$ & $24 \mathrm{hrs}$ & Alkali $(\mathrm{pH}=9)$ & Dynamic & $142.05 \pm 0.36$ & $86.61 \pm 0.17$ \\
\hline T25 & $100 \%$ ethanol & $10: 100$ & $6 \mathrm{hrs}$ & Acid (pH=3) & Static & $63.11 \pm 0.25$ & $56.21 \pm 0.09$ \\
\hline T26 & $100 \%$ ethanol & $10: 100$ & $6 \mathrm{hrs}$ & Acid (pH=3) & Dynamic & $83.03 \pm 0.36$ & $86.54 \pm 0.09$ \\
\hline T27 & $100 \%$ ethanol & $10: 100$ & $6 \mathrm{hrs}$ & Alkali $(\mathrm{pH}=9)$ & Static & $13.61 \pm 0$ & $20.54 \pm 0$ \\
\hline T28 & $100 \%$ ethanol & $10: 100$ & $6 \mathrm{hrs}$ & Alkali $(\mathrm{pH}=9)$ & Dynamic & $71.11 \pm 0.36$ & $52.75 \pm 0.15$ \\
\hline T29 & $100 \%$ ethanol & $10: 100$ & $24 \mathrm{hrs}$ & Acid $(\mathrm{pH}=3)$ & Static & $38.11 \pm 0.07$ & $57.68 \pm 0.15$ \\
\hline T30 & $100 \%$ ethanol & $10: 100$ & $24 \mathrm{hrs}$ & Acid $(\mathrm{pH}=3)$ & Dynamic & $74.36 \pm 0.45$ & $82.65 \pm 0.15$ \\
\hline T31 & $100 \%$ ethanol & $10: 100$ & $24 \mathrm{hrs}$ & Alkali $(\mathrm{pH}=9)$ & Static & $45.69 \pm 0.14$ & $49.6 \pm 0.09$ \\
\hline T32 & $100 \%$ ethanol & $10: 100$ & $24 \mathrm{hrs}$ & Alkali $(\mathrm{pH}=9)$ & Dynamic & $80.44 \pm 0.25$ & $80.24 \pm 0.09$ \\
\hline
\end{tabular}

\section{Statistical analysis}

The statistical analysis was done by Student's $t$-test, performed by software Stata version 16.0. Variations in blood parameter values are expressed as mean \pm standard deviation $(S D)$ and a $95 \%(p<0.05)$ confidence level was considered as statistically significant for all parameters analysed.

\section{RESULTS}

\section{Phytochemical screening}

The results of phytochemical screening showed the presence of alkaloids, flavonoids, tannins and anthraquinone and coumarin glycosides (Table 3 ).

\section{Quantitative analysis}

The quantitative analysis of total phenols showed that the treatment using ethanol $70 \%$ as solvent, a drug/solvent ratio of $5 \%$ and dynamic
Table 3: Phytochemical screening (+) positive result; (-) negative result.

\begin{tabular}{cc}
\hline Secondary compounds & Result \\
\hline Alkaloids & + \\
Flavonoids & + \\
Tannins & + \\
Anthraquinones glycosides & - \\
Cardiotonic glycosides & + \\
Coumarins glycosides & - \\
Saponins glycosides & - \\
\hline
\end{tabular}




\section{Table 4: Coagulation analysis results for control and diluted samples of raw and purified plant extracts.}

\begin{tabular}{|c|c|c|c|c|c|c|}
\hline $\begin{array}{l}\text { Type of } \\
\text { extract }\end{array}$ & $\begin{array}{c}\text { Group of } \\
\text { metabolites }\end{array}$ & Sample & PT average \pm SD (s) & APTT average \pm SD (s) & $\begin{array}{c}\text { HGB average } \pm \text { SD } \\
(\mathrm{g} / \mathrm{dL})\end{array}$ & $\begin{array}{c}\text { PLT average } \pm \text { SD } \\
\left(10^{3} / \mu \mathrm{L}\right)\end{array}$ \\
\hline \multirow{7}{*}{ Raw } & \multirow{3}{*}{ Total Phenols } & Control & $15.4 \pm 1.1$ & $24.4 \pm 2.7$ & $13.0 \pm 1.4$ & $188.7 \pm 10.0$ \\
\hline & & $1: 10$ & $17.4 \pm 0.4$ & $27.6 \pm 2.0$ & $11.3 \pm 2.5$ & $153.7 \pm 13.3$ \\
\hline & & $1: 15$ & $17.4 \pm 1.7$ & $25.1 \pm 2.8$ & $9.4 \pm 2.7$ & $130.3 \pm 30.4$ \\
\hline & \multirow{4}{*}{ Flavonoids } & Control & $15.6 \pm 1.0$ & $23.9 \pm 2.2$ & $13.0 \pm 1.4$ & $188.7 \pm 10.0$ \\
\hline & & $1: 5$ & $16.7 \pm 1.8$ & $36.4 \pm 6.2$ & $10.9 \pm 1.1$ & $161.7 \pm 11.1$ \\
\hline & & $1: 10$ & $16.6 \pm 1.3$ & $28.5 \pm 2.2$ & $11.3 \pm 1.2$ & $152.3 \pm 7.6$ \\
\hline & & $1: 15$ & $16.9 \pm 1.5$ & $27.2 \pm 0.6$ & $11.6 \pm 1.7$ & $145.3 \pm 13.3$ \\
\hline \multirow{8}{*}{ Purified } & \multirow[t]{3}{*}{ Total Phenols } & $1: 10$ & $16.0 \pm 0.6$ & $28.5 \pm 1.7$ & $9.7 \pm 0.5$ & $192.0 \pm 39.0$ \\
\hline & & $1: 15$ & $15.8 \pm 0.6$ & $29.2 \pm 1.7$ & $9.8 \pm 0.5$ & $145.7 \pm 24.8$ \\
\hline & & $1: 20$ & $16.1 \pm 0.5$ & $27.8 \pm 0.2$ & $9.8 \pm 1.6$ & $194.0 \pm 48.6$ \\
\hline & \multirow{5}{*}{ Flavonoids } & Control & $14.6 \pm 0.1$ & $23.4 \pm 1.3$ & $12.8 \pm 0.1$ & $226.7 \pm 33.5$ \\
\hline & & $1: 5$ & $17.2 \pm 0.9$ & $28.6 \pm 1.4$ & $11.1 \pm 1.2$ & $205.7 \pm 50.9$ \\
\hline & & $1: 10$ & $16.4 \pm 0.3$ & $25.8 \pm 0.2$ & $11.6 \pm 0.6$ & $183.0 \pm 17.1$ \\
\hline & & $1: 15$ & $16.4 \pm 0.4$ & $25.6 \pm 0.2$ & $11.7 \pm 0.4$ & $176.0 \pm 20.9$ \\
\hline & & $1: 20$ & $16.1 \pm 0.4$ & $25.3 \pm 0.5$ & $12.0 \pm 0.3$ & $184.7 \pm 16.9$ \\
\hline
\end{tabular}

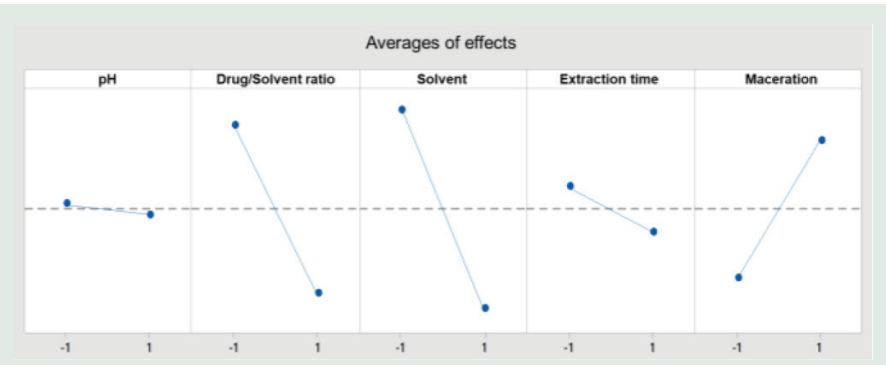

Figure 1: Average effects chart for total phenols.

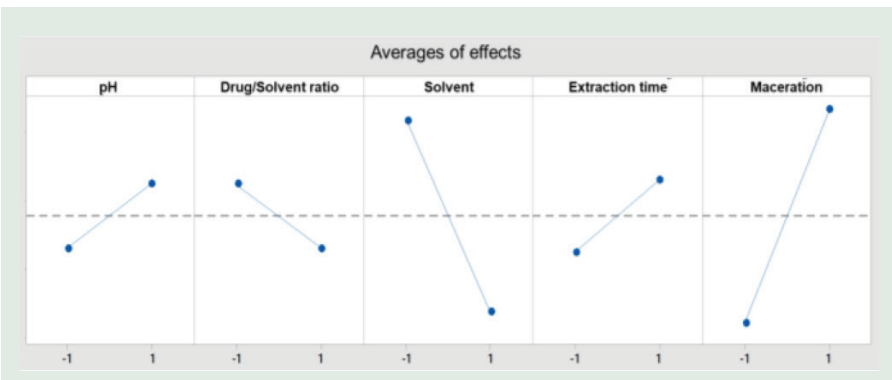

Figure 2: Average effects chart for flavonoids. maceration for 6 hrs resulted in the best combination for the extraction of this group of metabolites. The $\mathrm{pH}$ factor showed a relatively equal impact from $\mathrm{pH} 3$ and $\mathrm{pH}$ 9. Ethanol 70\%, a drug/solvent ratio of 5\%, $\mathrm{pH} 9$ and dynamic maceration for $24 \mathrm{hrs}$ was shown to be the best multifactorial condition for flavonoid extraction (Table 4, Figure 1 and 2).

\section{Coagulation analysis}

The non-purified SAE that was rich in total phenols showed major variations in APTT at the lowest extract dilution (1:5), while presenting a non-linear behaviour in the other dilutions. Some deviations were observed in PT for all dilutions; however, the average measurements were constant. The non-purified SAE that was rich in flavonoids showed a greater APTT variation at the lower dilution (1:5); however, observing the variations in PT parameters, a non-significant increase was exhibited for all dilutions (Figure 3, Table 4). Most parameter variations did not show statistical relevance, with the exception of the most concentrated dilution for APTT and the total phenol 1:10 extract for PT (Table 5).

In non-purified SAE that was rich in total phenols, the blood count parameters exhibited variations in all dilutions, presenting less HGB reduction at the lowest dilution (1:5), while the other extracts showed greater HGB reduction as the dilutions increased. The PLT count showed similar results, with a smaller decrease in PLT count at the lowest dilutions (1:5 and 1:10) and a greater reduction in PLT count at the highest dilutions (1:15 and 1:20). Variations in the non-purified flavonoid-rich SAE dilutions were observed and there was higher HGB dosage at the highest dilutions, especially in the treatment using the 1:15 dilution. However, the PLT count showed the opposite results, where a decreasing PLT count was observed at the lower dilutions (1:5 and 1:10) and a greater 


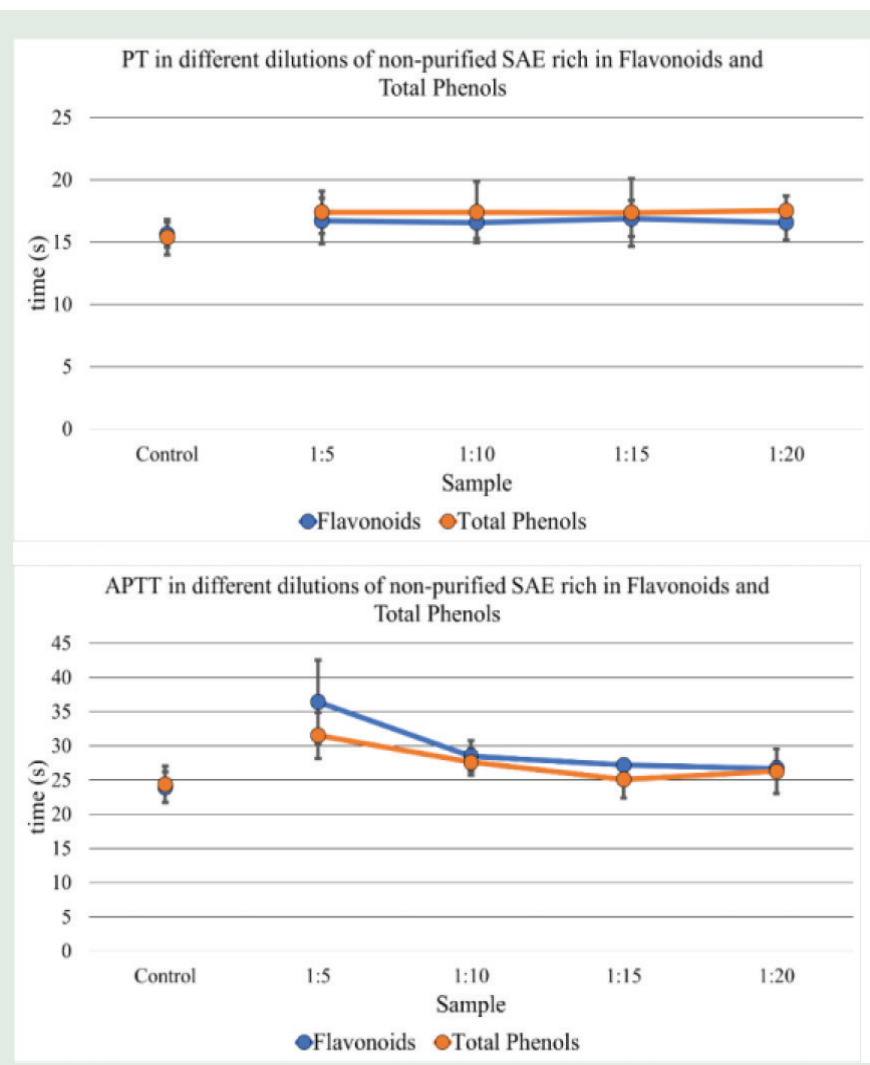

Figure 3: Mean alteration results of the parameters PT and APTT for non-purified SAE rich in phenols and flavonoids.

reduction was noted at higher dilutions (Figure 4, Table 4). Most HGB variations did not show statistical relevance, with the exception of the total phenol 1:20 extract; however, PLT variations were statistically relevant for both extracts in all dilutions (Table 5).

The purified SAE that was rich in total phenols showed a significant increase in APTT at 1:5 dilution, which was not observed in the other dilutions. When analysing the variations in $\mathrm{PT}$, all dilution results were similar and showed some increase over the control sample. The purified SAE that was rich in flavonoids showed a greater variation for both APTT and PT at the lowest extract dilution (1:5), while a decreasing in time was observed for both parameters in the intermediate dilutions (Figure 5, Table 4). Almost all parameter variations showed statistical relevance, with the exception of the total phenol 1:5 extract and the flavonoids 1:20 for APTT (Table 5).

The blood count parameters showed some decrease in HGB in all dilutions; however, the 1:15 sample showed the best result with lower reduction. When analysing the changes in the PLT count, there was no direct correlation to the extract dilution, since the 1:10 and 1:20 dilutions presented the best results with a smaller variation in the PLT number. The blood count parameters showed some reduction in HGB dosage for the highest diluted extracts, whereas the 1:5 dilution demonstrated the greatest reduction. When observing the PLT count, the scenario is the opposite, with a smaller decrease in PLT numbers at the lowest dilution (1:5) and a greater reduction at the higher dilutions (Figure 6, Table 4). Most PLT variations did not show statistical relevance, with the exception of the total phenol 1:15 extract. However, HGB variations were statistical relevant for almost all flavonoid extracts, with the exception of the 1:5 dilution (Table 5).
Haemoglobin dosage in different dilutions of non-purified SAE rich in Flavonoids and Total Phenols

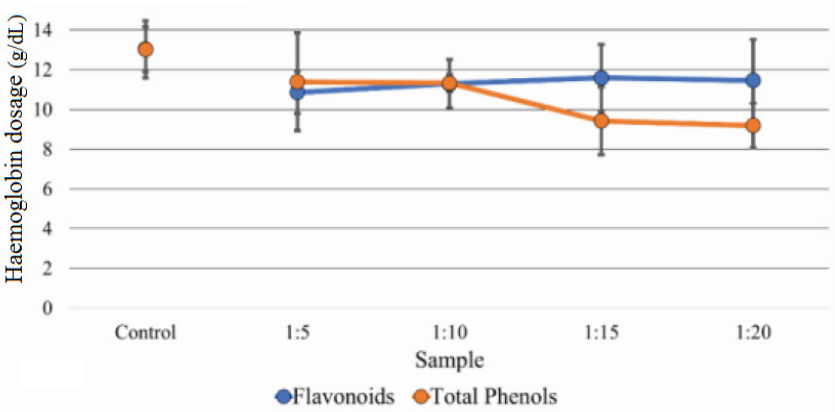

Platelets count in different dilutions of non-purified SAE rich in Flavonoids and Total Phenols

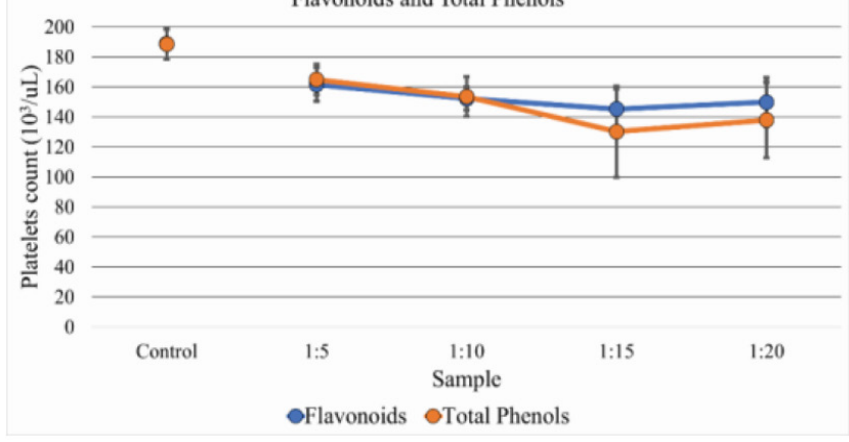

Figure 4: Average changes of the HGB and PLT parameters for non-purified SAE rich in phenols and flavonoids.

\section{DISCUSSION}

The secondary compounds produced by plants have demonstrated important pharmacological activities in several areas of application; thus, the medicinal interest in raw plant materials that are rich in these substances is growing. ${ }^{[19]}$ Several studies on species of the Dalbergia genus have shown the presence of secondary compounds and subsequently evaluated their biological actions.

\section{Phytochemical Screening}

The Fabaceae family has been studied by many authors and the genus Dalbergia is one of the most investigated among them, since this genus has relevant production of secondary metabolites, such as total phenols and flavonoids.

Ismail et al. ${ }^{[8]}$ and Yemitan and Adeyemi ${ }^{[5]}$ studied the pharmacological effects of Dalbergia saxatilis Hook. F. roots and phytochemical screening reported the presence of secondary compounds, such as alkaloids, flavonoids, tannins, triterpenoids, cardiotonic and saponin glycosides.

Chandra, Sachan and $\mathrm{Pal}^{[20]}$ detected the presence of several carbohydrates and total phenolic compounds, including flavonoids, in Dalbergia sissoo Roxb. leaves when investigating the effects on diarrhoea episodes. Hasan et al. ${ }^{[21]}$ evaluated several pharmacological aspects of Dalbergia candenatensis (Dennst.) Prain leaf extracts and the phytochemical screening conducted on this species identified the presence of total phenolic compounds including tannins and flavonoids, but obtained negative results for the presence of saponin glycosides.

When comparing the results of the present study with those observed in previous studies involving other Dalbergia species, the agreement of some secondary compounds among these species is notorious, since 
Rovetta, et al.: Anticoagulant Activity of Dalbergia ecastaphyllum (L.) Taub.

Table 5: Statistical analysis results of blood parameter for samples of raw and purified plant extracts.

\begin{tabular}{|c|c|c|c|c|c|c|}
\hline Type of extract & $\begin{array}{c}\text { Group of } \\
\text { metabolites }\end{array}$ & Sample & $\begin{array}{c}\text { PT } \\
\text { ( } p \text { value) }\end{array}$ & $\begin{array}{c}\text { APTT } \\
\text { ( } p \text { value) }\end{array}$ & $\begin{array}{c}\text { HGB } \\
\text { (p value) }\end{array}$ & $\begin{array}{c}\text { PLT } \\
\text { ( } p \text { value) }\end{array}$ \\
\hline \multirow{8}{*}{ Raw } & \multirow{4}{*}{ Total Phenols } & $1: 5$ & 0.269 & 0.046 & 0.272 & 0.045 \\
\hline & & $1: 10$ & 0.046 & 0.165 & 0.359 & 0.022 \\
\hline & & $1: 15$ & 0.172 & 0.768 & 0.112 & 0.034 \\
\hline & & $1: 20$ & 0.082 & 0.477 & 0.023 & 0.032 \\
\hline & \multirow{4}{*}{ Flavonoids } & $1: 5$ & 0.415 & 0.030 & 0.103 & 0.035 \\
\hline & & $1: 10$ & 0.364 & 0.065 & 0.185 & 0.007 \\
\hline & & $1: 15$ & 0.272 & 0.069 & 0.324 & 0.011 \\
\hline & & $1: 20$ & 0.391 & 0.119 & 0.339 & 0.024 \\
\hline \multirow{8}{*}{ Purified } & \multirow{4}{*}{ Total Phenols } & 1:5 & 0.021 & 0.083 & 0.134 & 0.130 \\
\hline & & $1: 10$ & 0.012 & 0.015 & 0.115 & 0.192 \\
\hline & & 1:15 & 0.019 & 0.009 & 0.139 & 0.040 \\
\hline & & $1: 20$ & 0.007 & 0.005 & 0.285 & 0.232 \\
\hline & \multirow{4}{*}{ Flavonoids } & 1:5 & 0.007 & 0.009 & 0.085 & 0.583 \\
\hline & & $1: 10$ & 0.0003 & 0.039 & 0.023 & 0.114 \\
\hline & & $1: 15$ & 0.001 & 0.048 & 0.009 & 0.090 \\
\hline & & $1: 20$ & 0.002 & 0.079 & 0.006 & 0.124 \\
\hline
\end{tabular}

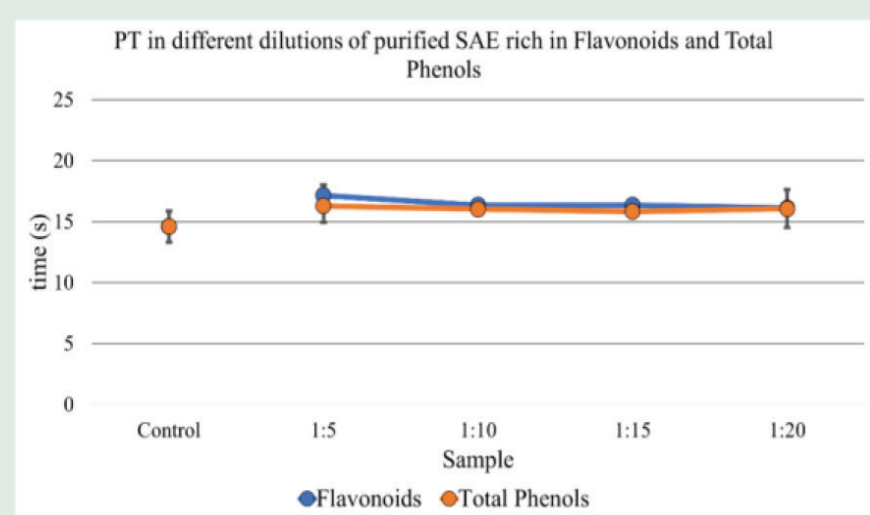

APTT in different dilutions of purified SAE rich in Flavonoids and Total Phenols

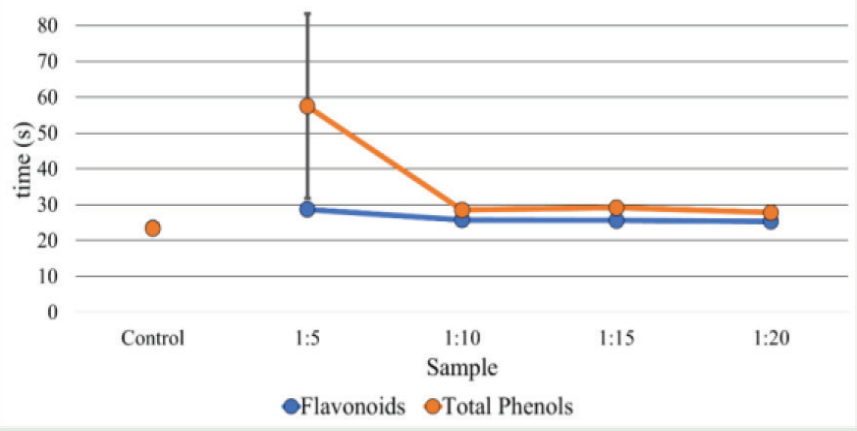

Figure 5: Mean alteration results of the parameters PT and APTT for purified SAE rich in total phenols and flavonoids.

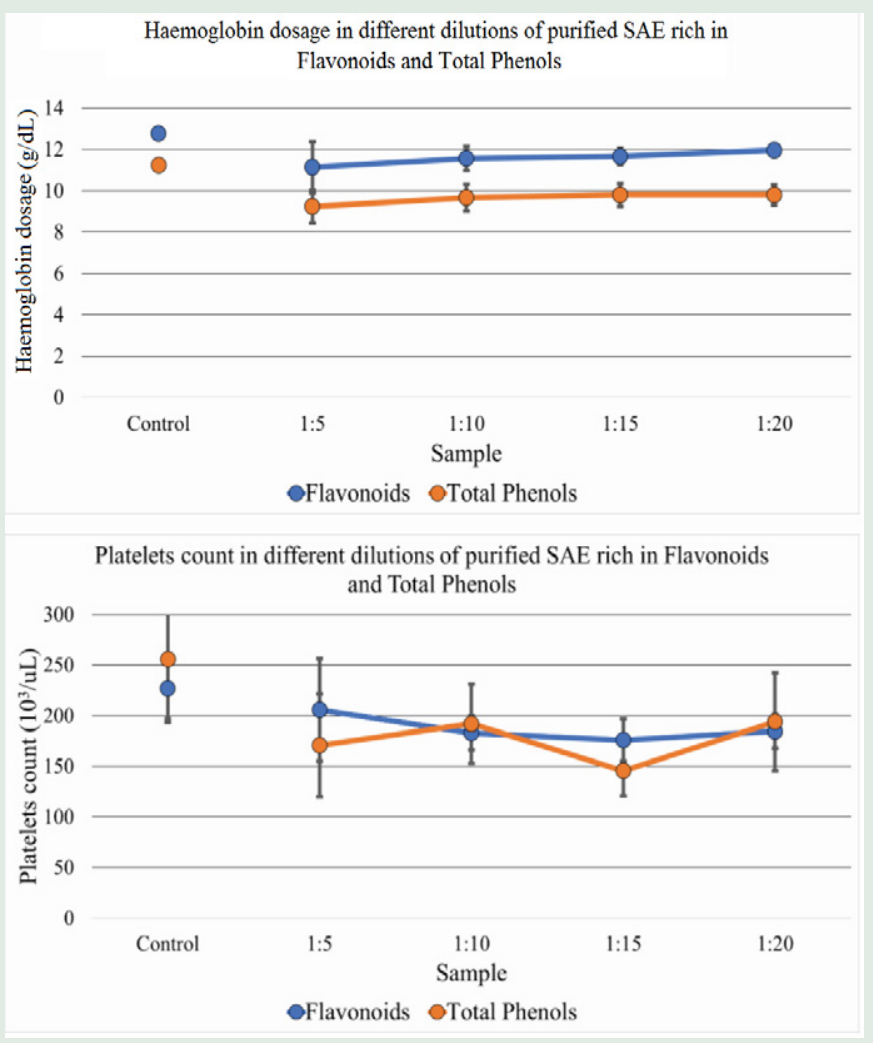

Figure 6: Average changes in the parameters HGB and PLT for purified SAE rich in total phenols and flavonoids. 
most were also present, suggesting that this genus has congruent characteristics regarding the production of phenolic compounds.

\section{Quantitative Analysis}

The quantitative multifactorial analysis using DOE helped investigate the effects of different variables at the same time. The tool consists of a series of tests in which deliberate changes are made to the input variables, supporting the identification of conditions that affect plant material extraction and then determining the settings for factors that optimize results. The use of DOE corroborated the decision-making process, based on highly complex analyses and statistical studies.

After DOE analysis, the extractive condition had a definitive result for all five factors, showing that ethanol $70 \%$, a drug/solvent ratio of $5 \%, \mathrm{pH}$ 9 and dynamic maceration for 24 hrs is statistically the best extraction of flavonoids present in Dalbergia ecastaphyllum (L.) Taub. in the case of total phenols, DOE analysis had a definitive result for four factors, showing that ethanol $70 \%$, a drug/solvent ratio of $5 \%$ and dynamic maceration for $6 \mathrm{hrs}$ is statistically the best extraction. Despite results tending to show $\mathrm{pH} 3$ as a better extractive condition, the difference for $\mathrm{pH} 9$ was almost inexistent; therefore, the most effective $\mathrm{pH}$ for the extraction of total phenols is still inconclusive.

\section{Coagulation Analysis}

There were several coagulation analyses conducted in the Fabaceae family species. The study conducted by Pereira and Brazón ${ }^{[22]}$ evaluated the impact of Brownea grandiceps Jacq. aqueous flower extracts on human blood coagulation by measuring PT and APTT, observing that low concentrations of the extract decreased the PT, while higher concentrations contributed to increasing it, suggesting that the extract acts as a procoagulant and as anticoagulant depending on compounds concentration, although there was no evidence of which compounds could be involved in such an action.

Cordier et al. ${ }^{[23]}$ also evaluated the coagulation and haemolysis processes in several Fabaceae species, such as Dichrostachys cinerea (L.) Wright and Arn. roots, Cassia petersiana Belle., Mundulea sericea Willd. A. Chev. roots, Medicago sativa L. leaves and Dalbergia melanoxylon Guill and Perr. bark. The authors observed a significant increase both in PT and APTT, with Cassia petersiana Belle. and Dalbergia melanoxylon Guill. and Perr. The results on blood parameters showed that Dalbergia melanoxylon Guill and Perr. significantly increased haemolysis in the studied concentrations, when using aqueous and methanolic extracts.

Hasan et al. ${ }^{[21]}$ studied Dalbergia candenatensis (Dennst.) Prain leaf extract to evaluate the impact on human blood by comparing the PT to warfarin, a classic synthetic drug used as an anticoagulant. The results showed an increasing in proportional PT to the extract concentration used in the assay; thus, it was suggested that this event is dose-dependent. The same authors conducted a haemolysis test and evaluated different concentrations of extracts to inhibit the haemolytic process, identifying that higher-dose extracts resulted in greater haemolysis inhibition.

Wadekar et al. ${ }^{[24]}$ studied the effects of aqueous and alcoholic extracts of Dalbergia sissoo Roxb. bark on human plasma by measuring the PT and found that clot dissolution increased as the sample concentration increased, showing a moderate anticoagulant activity. The same authors suggested a possible mechanism for this anticoagulant effect and pointed out that phenolic compounds - especially tannins and flavonoids - are involved with the anticoagulant property, although did not specify how it happens.

The results of previously described studies show that the Dalbergia genus has compounds that certainly act on the coagulation process and PLT inhibition in human blood in vitro, which corroborates the results found in the present study, since both non-purified and purified extracts analysed at different dilutions with ethanol $70 \%$, a drug/solvent ratio of $5 \%, \mathrm{pH} 9$ and dynamic maceration for 6 and $24 \mathrm{hrs}$ caused an increase in $\mathrm{PT}$ and APTT in human blood in vitro.

Therefore, Dalbergia ecastaphyllum (L.) Taub. leaf extract probably has some level of intervention on the coagulation process, especially in the APTT levels for the lower dilution samples, while no major variations were observed in PT for most samples. Red cells and PLT count showed a reduction in all samples; however, the overall safety of the leaf extract is inconclusive. Wadekar et al. described the mechanism of action as being related with the phenolic compounds, which could be the same mechanism observed in this study. ${ }^{[24]}$

\section{CONCLUSION}

From the present study, it can be suggested that the purified Dalbergia ecastaphyllum (L.) Taub. dried leaf SAEs mainly induced an anticoagulant activity. The flavonoids and total phenols present in these extracts might be responsible for the development of an important role on the coagulation cascade and platelet maintenance; nonetheless, more investigation is required to identify which molecule interferes in that process. In addition, it can be inferred that Dalbergia ecastaphyllum (L.) Taub. leaves have a strong potential as a future drug for coagulation disorder treatments.

\section{ACKNOWLEDGEMENT}

The authors are grateful to the Pharmacy, Clinical Analysis and Analytical Chemistry laboratories of Centro Universitário FMABC, for providing facilities for carrying out the study.

\section{Financial support and sponsorship}

Nil.

\section{CONFLICT OF INTEREST}

The authors declare no conflict of interest.

\section{ABBREVIATIONS}

APTT: Activated Partially Thromboplastin Time; ARF: Aqueous Raw Fraction; CBC: Complete Blood Count; DOE: DoE, Minitab ${ }^{\oplus}$ EDTA: Ethylenediamine Tetra-Acetic Acid; ERE: Ethanolic Raw Extracts; HGB: Haemoglobin; PLT: Platelet; PT: Prothrombin Time; SAE: Saline Aqueous Extract.

\section{REFERENCES}

1. Rodger L, Bick GM. Physiology of Hemostasis. Clin Lab Med. 1994;14(4):677-707.

2. Franchini M, Lippi G, Manzato F. Recent acquisitions in the pathophysiology, diagnosis and treatment of disseminated intravascular coagulation. Thromb J. 2006;4(1):1-9.

3. Caldwell SH, Hoffman M, Lisman T, Macik BG, Northup PG, Reddy KR. Coagulation Disorders and Hemostasis in Liver Disease: Pathophysiology and Critical Assessment of Current Management. Hepatology. 2006;44(4):1039-46.

4. Born G, Patrono C. Antiplatelet drugs. Br J Pharmacol. 2006;147(Suppl 1):S241-51.

5. Yemitan OK, Adeyemi OO. Mechanistic assessment of the analgesic, antiinflammatory and antipyretic actions of Dalbergia saxatilis in animal models. Pharm Biol. 2017;55(1): 898-905.

6. Saluk-juszczak J, Pawlaczyk I, Olas B, Kołodziejczyk J, Ponczek M, Nowak P, et al. The effect of polyphenolic-polysaccharide conjugates from selected medicinal plants of Asteraceae family on the peroxynitrite-induced changes in blood platelet proteins. Int J Biol Macromol. 2010;47(5):700-5.

7. Zeni ALB. O uso de plantas medicinais em uma comunidade rural de Mata Atlântica - Nova Rússia, SC. Neotrop Biol Conserv. 2011;6(1):55-63.

8. Ismail HF, Zezi AU, Hamza YA, Habib U. Analgesic, anti-inflammatory and antipyretic activities of the methanol leaf extract of Dalbergia saxatilis Hook. F in rats and mice. J Ethnopharmacol. 2015;1-5.

9. Guedes MM, Albuquerque RS, Soares-maciel RS, Freitas MA, Silva VA, Lima EO, et al. Isolation of phytosterols of Dalbergia ecastaphyllum (L.) Taub. (Legumi- 
nosae) and modulation of antibiotic resistance by a possible membrane effect. Arab J Chem. 2019;12(7):1576-80.

10. Trease, GE; Evans W. Pharmacopoeial and related drugs of biological origin. In: Pharmacognosy. 16 ${ }^{\text {th }}$ ed. London: Saunders Elsevier. 2009;169-482.

11. Harborne JB. Methods of plant analysis. In: Harborne JB, editor. Phytochemical Methods A Guide to Modern Techniques of Plant Analysis. $3^{\text {rd }}$ ed. London: Chapman and Hall. 1998;1-32.

12. Bonoli M, Verardo V, Marconi E, Caboni MF. Antioxidant phenols in barley (Hordeum vulgare L.) flour: comparative spectrophotometric study among extraction methods of free and bound phenolic compounds. J Agric Food Chem. 2004;52(16):5195-200.

13. Mole $S$, Waterman PG. A critical analysis of techniques for measuring tannins in ecological studies. Oecologia. 1987;72(1):137-47.

14. Woisky RG, Salatino A. Analysis of propolis: Some parameters and procedures for chemical quality control. J Apic Res. 1998;37(1):99-105.

15. Marston A, Hostettmann K. Separation and Quantification of Flavonoids. In: Oyvind MA; Kenneth RM, editor. Flavonoids - Chemistry, Biochemistry and Applications. $1^{\text {st }}$ ed. Boca Raton: CRC Press. 2005;1-36.

16. Stalikas CD. Extraction, separation and detection methods for phenolic acids and flavonoids. J Sep Sci. 2007;30(18):3268-95.

17. Silva L, Alves J, Siqueira E, Neto M, Abreu L, Tavares J, et al. Isolation and
Identification of the Five Novel Flavonoids from Genipa americana Leaves. Molecules. 2018;23(10):1-13.

18. Gonzalez-Covarrubias V, Dane A, Hankemeier T, Vreeken RJ. The influence of citrate, EDTA and heparin anticoagulants to human plasma LC-MS lipidomic profiling. Metabolomics. 2013;9(2):337-48.

19. Siqueira D, Chaves DA, Costa S, Almeida APD. Metabólitos secundários de origem vegetal: Uma fonte potencial de fármacos antitrombóticos. Quim Nova. 2010;33(1):172-80.

20. Chandra P, Sachan N, Pal D. Protective effect of Dalbergia sissoo Roxb. ex DC. (family: Fabaceae) leaves against experimentally induced diarrhoea and peristalsis in mice. Toxicol Ind Health. 2015;31(12):1229-35.

21. Hasan M, Acharzo AK, Das AK, Rahman S. In vivo and in vitro Evaluation of Pharmacological Potentials of Secondary Bioactive Metabolites of Dalbergia candenatensis Leaves. Evidence-based Complement Altern Med. 2017; 2017(1):1-10.

22. Pereira B, Brazón J. Aqueous extract from Brownea grandiceps flowers with effect on coagulation and fibrinolytic system. J Ethnopharmacol. 2015;160:6-13.

23. Cordier W, Cromarty AD, Botha E, Steenkamp V. Effects of selected South African plant extracts on haemolysis and coagulation. Hum Exp Toxicol. 2015;31(3):250-7.

24. Wadekar JB, Sawant RL, Kirtane SV, Sanklecha KR, Ghodechor AS. In vitro Anti-coagulant Activity of Dalbergia sissoo Bark. J Phytopharm. 2017;6(5):297-9.

\section{GRAPHICAL ABSTRACT}

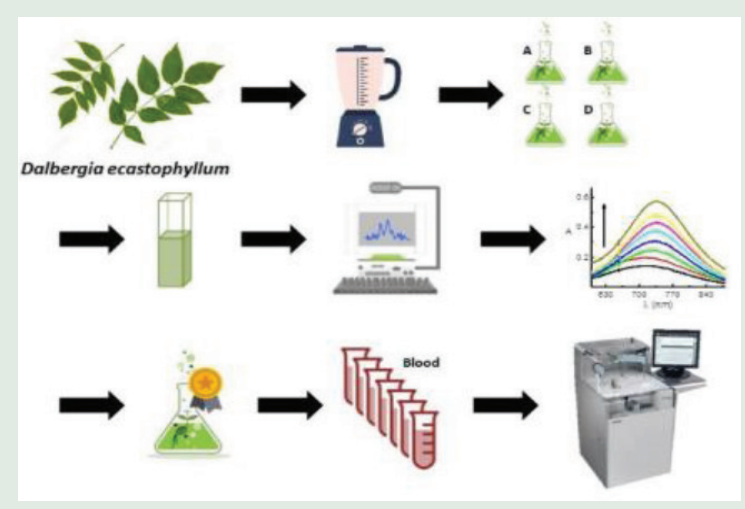

\section{SUMMARY}

The present study consisted of Dalbergia ecastaphyllum (L.) Taub. dried and powdered leaves as plant material, submitted to several extract conditions (agitation, extractor liquid concentrations, its $\mathrm{pH}$, plant drug proportions and extraction time) which resulted in 32 treatments. Afterwards were analyzed by spectrophotometry to stablish the most efficient extraction condition for total phenols and flavonoid fractions. From the most efficient extract, dilutions were carried out and analysis were conducted to evaluate their impact on human blood coagulation parameters (PT, APTT, hemoglobin and platelet counting).

Cite this article: Rovetta ER, Magenta MAG, Gascon TM, Fonseca FLA, Gama RM, Armando-Jr J, Moya HD. Anticoagulant Activity of Crude and Phenolic Extracts of Dalbergia ecastaphyllum (L.) Taub. Dried Leaves. Pharmacog Res. 2021;13(3):121-8. 